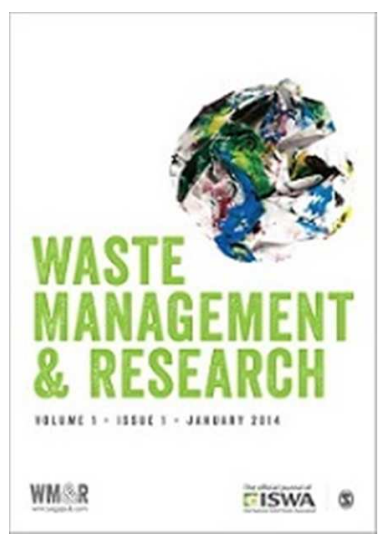

\title{
Recycling of typical supercapacitor materials
}

\begin{tabular}{|c|c|}
\hline Journal: & Waste Management \& Research \\
\hline Manuscript ID: & WMR-15-0214 \\
\hline Manuscript Type: & Original article: 35,000 characters \\
\hline Date Submitted by the Author: & 22-Mar-2015 \\
\hline Complete List of Authors: & $\begin{array}{l}\text { Trapalis, Christos; NCSR Demokritos, inn } \\
\text { Vermisoglou, Eleni; NCSR Demokritos, } 15343 \\
\text { Todorova, Nadia; NCSR Demokritos, } 15343 \\
\text { Giannakopoulou, Tatiana; NCSR Demokritos, } 15343 \\
\text { Lekakou, Constantina }\end{array}$ \\
\hline Keywords: & Supercapacitor, recycling, carbonaceous materials, TEABF4, h-PVDF \\
\hline Abstract: & $\begin{array}{l}\text { A simple, facile and low cost method for recycling of supercapacitor } \\
\text { materials is followed. This process aims to recover some fundamental } \\
\text { components of a used supercapacitor namely the electrolyte salt TEABF4 } \\
\text { (tetraethyl ammonium tetrafluoroborate) dissolved in an aprotic organic } \\
\text { solvent such as ACN (acetonitrile), the carbonaceous material (activated } \\
\text { charcoal, CNTs) purified, the current collector (aluminum foil) and the } \\
\text { separator (paper) for further utilization. The method includes mechanical } \\
\text { shredding of the supercapacitor in order to reduce its size and separation } \\
\text { of aluminum foil and paper from the carbonaceous resources containing } \\
\text { TEABF4 by sieving. The extraction of TEABF4 from the carbonaceous } \\
\text { material was based on its solubility in water and subsequent separation } \\
\text { through filtering and distillation. Cyclic voltammetry curve of the recycled } \\
\text { carbonaceous material revealed supercapacitor behavior allowing a } \\
\text { potential reutilization. Furthermore, since BF4- stemming from TEABF4 can } \\
\text { be slowly hydrolyzed in aqueous environment releasing thus F- anions } \\
\text { which are hazardous we went on to their gradual trapping with calcium } \\
\text { acetate and conversion to non hazardous CaF2. }\end{array}$ \\
\hline
\end{tabular}

\section{SCHOLARONE $^{m}$ \\ Manuscripts}




\title{
Recycling of typical supercapacitor materials
}

\author{
Eleni C. Vermisoglou*, Nadia Todorova*, Tatiana Giannakopoulou*,
} Constantina Lekakou ${ }^{* *}$, Christos Trapalis ${ }^{*}$

"Institute of Nanoscience \& Nanotechnology, "Demokritos", 153 43, Agia Paraskevi, Attikis, Greece

${ }^{* *}$ Division of Mechanical, Medical, and Aerospace Engineering, Faculty of Engineering and Physical Sciences, University of Surrey, Guildford GU2 7XH, UK

Keywords: recycling, supercapacitor, tetraethyl ammonium tetrafluoroborate, activated charcoal, acetonitrile, aluminium, paper, separation.

Corresponding author: Dr. Christos Trapalis, Institute of Nanoscience \& Nanotechnology, "Demokritos", 153 43, Agia Paraskevi, Attikis, Greece.

Tel: +302106503347 ;

e -mail: c.trapalis@inn.demokritos.gr 


\begin{abstract}
A simple, facile and low cost method for recycling of supercapacitor materials is followed. This process aims to recover some fundamental components of a used supercapacitor namely the electrolyte salt $\mathrm{TEABF}_{4}$ (tetraethyl ammonium tetrafluoroborate) dissolved in an aprotic organic solvent such as ACN (acetonitrile), the carbonaceous material (activated charcoal, CNTs) purified, the current collector (aluminum foil) and the separator (paper) for further utilization. The method includes mechanical shredding of the supercapacitor in order to reduce its size and separation of aluminum foil and paper from the carbonaceous resources containing $\mathrm{TEABF}_{4}$ by sieving. The extraction of $\mathrm{TEABF}_{4}$ from the carbonaceous material was based on its solubility in water and subsequent separation through filtering and distillation. Cyclic voltammetry curve of the recycled carbonaceous material revealed supercapacitor behavior allowing a potential reutilization. Furthermore, since $\mathrm{BF}_{4}^{-}$stemming from $\mathrm{TEABF}_{4}$ can be slowly hydrolyzed in aqueous environment releasing thus $\mathrm{F}^{-}$anions which are hazardous we went on to their gradual trapping with calcium acetate and conversion to non hazardous $\mathrm{CaF}_{2}$.
\end{abstract}

\title{
Keywords
}

Supercapacitor, recycling, carbonaceous materials, $\mathrm{TEABF}_{4}$, h-PVDF, Butanone

\section{Introduction}

Environmental concern, in terms of limiting the use of finite resources and management of waste disposal, has led to increasing demand to recycle materials at the end of their useful life. Recycling ultimately leads to resource and energy saving 
that would otherwise be expended by extracting virgin raw materials from the environment in order to produce goods that could also be manufactured from recycled waste materials. The major commercialization barriers are lack of adequate markets, high recycling cost, and lower quality of the recyclates. The recycling of engineering materials will contribute to sustainable development of industrial processes. Particularly, the recycling of the carbonaceous substances of a supercapacitor is very interesting in order to use them again in other applications. For example carbon fibers and epoxy resins are used for critical applications in the aerospace industry (Pickering, 2006, Jiang et al, 2008, Jiang et al, 2009, Pimenta et al, 2010, Pang et al, 2011) as electromagnetic interference shielding materials (Wong et al, 2010), in automotive industry, in sports and recreation facilities, boat and shipbuilding and in wind energy generation for wind turbine blades (Yang et al, 2012). Aluminum recovery is also of high importance since aluminum alloy matrix composites have been commercialized for automobile engine parts and outboard engine parts etc., because of their high specific tensile strength, elastic modulus and high wear resistance (Nishida, 2001). Recycling of paper is critically important since wood is not only the major feedstock for the global paper industry but also covers part of the energy used in the pulp and paper industry (Laurijssen et al, 2010).

There are three main categories of recycling technologies for composite materials: mechanical, thermal and chemical recycling. Mechanical techniques (Howarth et al, 2014, Lotfi et al, 2014) involve the use of grinding techniques such as slow speed cutting or crushing mill to comminute the scrap material (Pickering et al, 2000). The recyclable products may include fillers and fibrous materials in different sizes suitable for reuse in new composite materials (Kennerley et al, 1998). Cyclones (Richard et al, 2011) and sieves (Luo et al, 2013) are typically used to classify the shredded materials 
(Yang et al, 2012, Piñero-Hernanz et al, 2008). Thermal recycling involves processes at high temperatures in order to break the scrap composite down. Thermal processing can be divided to three main categories: a) Incineration (Morris, 1996, Merrild et al, 2012, Wang et al, 2012) b) Combustion (Miyamoto, 2003, Asokan et al, 2005) c) Pyrolysis (de Marco et al, 2007, Santini et al, 2012). Nevertheless, the classification of incineration and combustion at the recycling technology is dubious. In a pyrolysis process the material is heated at high temperature in the absence of oxygen and it breaks down in lower molecular weight substances and a carbon char is produced (Jiang et al, 2008). Chemical recycling involves the process for chemical depolymerization (Plichta et al, 2014) or removal of the matrix by using chemical dissolution reagents for liberation of carbonaceous materials such as carbon fibers (Oliveux et al, 2013). The dissolution process is often called solvolysis, and depending on the solvent can be classified as: hydrolysis (Song et al, 2014, Tsintzou et al, 2012), glycolysis (López-Fonseca et al, 2010), and acid digestion (Pickering et al, 2000, Petterson et al, 1994, Bo et al, 2007).

Since Electrochemical capacitors (ECs), also known as supercapacitors, are used as electrical energy storage devices in many fields and compared to traditional energy storage devices possess advantages such as high-power capability, long lifetime, low weight, and less maintenance costs their recycling is of major importance (Wang et al, 2011, Kötz et al, 2000). A typical supercapacitor is composed of aluminum foil, activated charcoal enriched with CNTs (carbon nanotubes) and/or graphenes, metal oxides, PVDF (polyvinylidene difluoride) (Chen et al, 2004), NMP (N-methyl-2pyrrolidone) and paper as a separator. Polymer foil is also used for packaging purposes. It may also contain $\mathrm{ACN}$ as a solvent and $\mathrm{TEABF}_{4}$, often used as a common organic electrolyte (Vermisoglou et al, 2014). Activated charcoal is chosen as a 
material for supercapacitor electrodes due to its high specific surface area which exceeds $1000 \mathrm{~m}^{2} / \mathrm{g}$ (Jain et al, 2014). Single layer graphene material has a calculated specific surface area of $2630 \mathrm{~m}^{2} / \mathrm{g}$ which could lead theoretically to a capacitor of $550 \mathrm{~F} / \mathrm{g}$ (Liu et al, 2010). On the other hand carbon nanotubes can greatly improve capacitor performance, due to their highly wettable surface area and high conductivity (Fedorovskaya et al, 2014). Transition metal oxides (such as ruthenium dioxide) can also be used because they exhibit enhanced pseudocapacitance (Wang et al, 2014). PVDF dissolved in NMP is mixed with an active storage material such as activated charcoal/CNTs. This slurry is cast onto the current collector and the NMP is evaporated to form a composite or paste electrode. PVDF is used because it is chemically inert over the potential range used and does not react with the electrolyte. The paper separates physically the two electrodes and is permeable for the conducting ions. Aluminum foil is used as current collector which connects the electrodes to the capacitor's terminals. PVDF is the standard binder material used in the production of composite electrodes.

In the present study a procedure for recycling of the major components of a used supercapacitor is described. Shredding in small pieces and sieving of a real used supercapacitor was applied in order to explore the ability of separation and recovery of its components. In addition, slurry with chemical composition simulating that of a used supercapacitor was prepared with increased quantities of the hazardous typical ingredients in order to facilitate their identification. Furthermore, for the hazardous component $\mathrm{TEABF}_{4}$ which hydrolyzes in water producing $\mathrm{F}^{-}$anions (Yoshioka et al, 2007, Katagiri et al, 2006) a handling method is proposed. 


\section{Materials and Methods}

\section{Materials}

Activated Charcoal was purchased by Sigma-Aldrich, CNTs by EMS (China), NMP $\left(\mathrm{C}_{5} \mathrm{H}_{9} \mathrm{NO}, 99+\%\right)$ by Alfa Aesar, ACN $\left(\mathrm{C}_{2} \mathrm{H}_{3} \mathrm{~N}, 99.8+\%\right)$, PVDF $\left(-\left(\mathrm{C}_{2} \mathrm{H}_{2} \mathrm{~F}_{2}\right)_{\mathrm{n}^{-}}\right)$by Alfa Aesar, $\mathrm{TEABF}_{4}\left(\left(\mathrm{C}_{2} \mathrm{H}_{5}\right)_{4} \mathrm{~N}\left(\mathrm{BF}_{4}\right), 99 \%\right)$ by Alfa Aesar and Butanone (Ethyl Methyl Ketone, $\mathrm{C}_{4} \mathrm{H}_{8} \mathrm{O}, 99.5+\%$ ) by Chem Lab.

\section{Preparation of a simulated used supercapacitor}

A mixture with all the typical used in a supercapacitor was prepared as follows: $5.71 \mathrm{~g}$ activated charcoal was dispersed in $5.0 \mathrm{~g}$ NMP followed by addition of $0.2955 \mathrm{~g}$ PVDF under stirring [A]. Separately, $0.0090 \mathrm{~g}$ CNTs was dispersed in $3.14 \mathrm{~g}$ NMP [B]. The dispersion [B] was added to [A] giving a mixture labeled [C]. In order to reduce the viscosity and facilitate the stirring of the slurry $4.0 \mathrm{~g}$ NMP were added in [C] and the whole was stirred for $3 \mathrm{~h}$. Then [C] was spread onto a glass plate and was dried in oven at $120{ }^{\circ} \mathrm{C}$ for $2 \mathrm{~h}$. After drying, $5.173 \mathrm{~g}$ of material labeled SP1 were obtained with content in activated charcoal $\sim 95 \%$, in CNTs $\sim 0.15 \%$, and PVDF $\sim 5 \%$. Separately, $2.0 \mathrm{~g} \mathrm{TEABF}_{4}$ were dissolved in $15.0 \mathrm{~g} \mathrm{ACN}$ [D] and mixed with $5.0 \mathrm{~g}$ of SP1 under stirring for $1 \mathrm{~h}[\mathrm{E}]$.

\section{Methodology of recycling}

The recycling methodology developed in our laboratory could be divided in the next steps:

a) Mechanical shredding of supercapacitor in order to reduce its size using commercial paper-cut machine (Q-CONNECT MICRO-CUT 12). 
b) Separation of aluminum foil and paper from the carbonaceous resources as well as PVDF and $\mathrm{TEABF}_{4}$ by use of laboratory sieves (IMPACT Company).

c) Extraction of $\mathrm{TEABF}_{4}$ from the carbonaceous material and recovery of ACN by chemical procedures, such as filtering, distillation in rotary evaporator (Buchi, R210/215) and drying in oven.

\section{Characterization}

Siemens D500 X-ray diffractometer was used for the XRD measurements. The FTIR transmittance spectra of the samples (KBr pellets) were measured on EQUINOX 55/5, Bruker instrument. SEM characterization was performed using a FEI Inspect SEM. The capacitive behavior of the materials was investigated on a Metrohm Autolab PGSTAT302 potentiometer performing cyclic voltammetry (CV) tests. The twoelectrode standard stainless steel test cell (HS Test Cell, Hohsen Corporation, Japan) was used as a supercapacitor test fixture. The two electrode configuration was used because it provides directly the material performance for electrochemical capacitors.

\section{Results and Discussion}

\section{Mechanical shredding of supercapacitor.}

The first step of the recycling procedure involves the mechanical shredding of the supercapacitor accomplished by the paper-cut machine. A typical supercapacitor (Figure 1a) was used for mechanical shredding. The shredding was necessary in order to cut the supercapacitor into small pieces and recover easier the aluminum and carbon content, facilitating thus the process for removing the hazardous ingredients $\mathrm{ACN}, \mathrm{TEABF}_{4}$. The supercapacitor was easily cut during the shredding procedure 
into small pieces with dimensions $3 \mathrm{~mm}$ x $9 \mathrm{~mm}$ (Figure 1b). Simultaneously the aluminum was detached from supercapacitor.
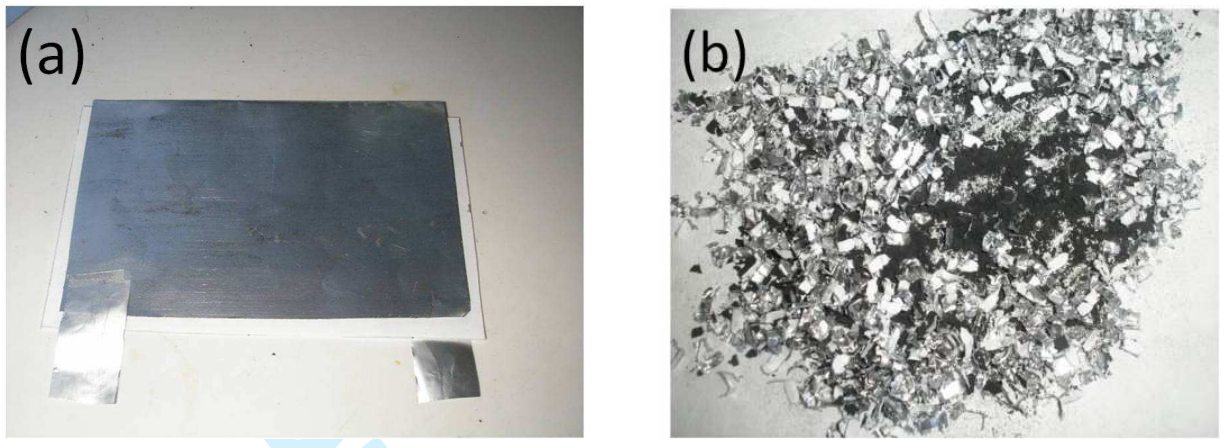

Figure 1. (a) Supercapacitor (donated by the University of Surrey) before mechanical shredding and (b) after mechanical shredding.

\section{Separation of aluminum foil and paper from the carbonaceous resources}

The separation of aluminum and paper from the carbonaceous resources as well as PVDF and $\mathrm{TEABF}_{4}$ was carried out using three laboratory test sieves with apertures of $500 \mu \mathrm{m}, 250 \mu \mathrm{m}$ and $125 \mu \mathrm{m}$. The products of the separation procedure are shown in Figure 2. 


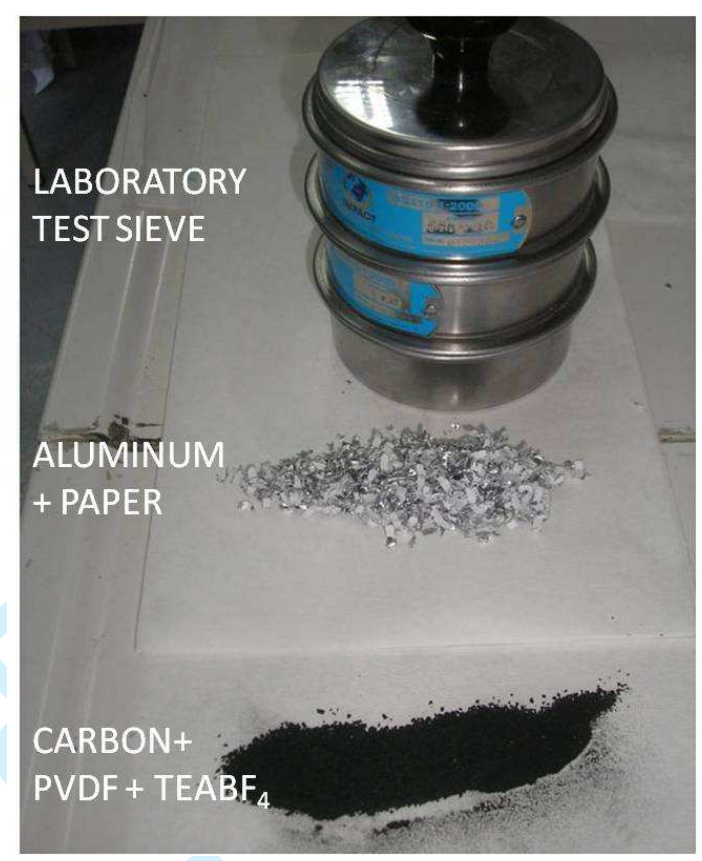

Figure 2. Aluminum and paper separated from carbon, $\mathrm{PVDF}$ and $\mathrm{TEABF}_{4}$ by three laboratory test sieves.

\section{Extraction of $\mathrm{TEABF}_{4}$ from the carbonaceous material}

The extraction of the solid electrolyte $\mathrm{TEABF}_{4}$ from the carbonaceous material as well as the purification of this material from h-PVDF (PVDF after heating at $120{ }^{\circ} \mathrm{C}$ for $2 \mathrm{~h}$ ) was carried out utilizing the solubility of $\mathrm{TEABF}_{4}$ in water and the solubility of PVDF in butanone. This approach also allowed the separation through stirring without/or under reflux, filtering and distillation with rotary evaporator.

Since the amount of $\mathrm{TEABF}_{4}$ in the supercapacitor was quite small, it was difficult from the above procedure to verify their presence. The $\mathrm{TEABF}_{4}$ was separated from slurry containing all the typical ingredients of a used supercapacitor in the same ratios and enhanced amounts (sample SP1).

Recycling of a simulated supercapacitor 
The processes involved below aim at the separation of the components $\mathrm{TEABF}_{4}$, $\mathrm{ACN}$ and carbonaceous material comprising the simulated supercapacitor. These processes are based in the fact that:

(a) $\mathrm{ACN}$ is miscible with water and $\mathrm{TEABF}_{4}$ is soluble in both solvents and $\mathrm{BF}_{4}^{-}$ slightly hydrolyzes in aqueous solutions up to $6 \mathrm{~h}$.

(b) NMP (b.p. $202-204{ }^{\circ} \mathrm{C}$ ) has practically been evaporated during the drying in the oven.

(c) PVDF has solubility in solvents such as butanone which is volatile, facilitates distillation and has low toxicity.

The recycling process is summarized in the following diagram (Figure 3) 


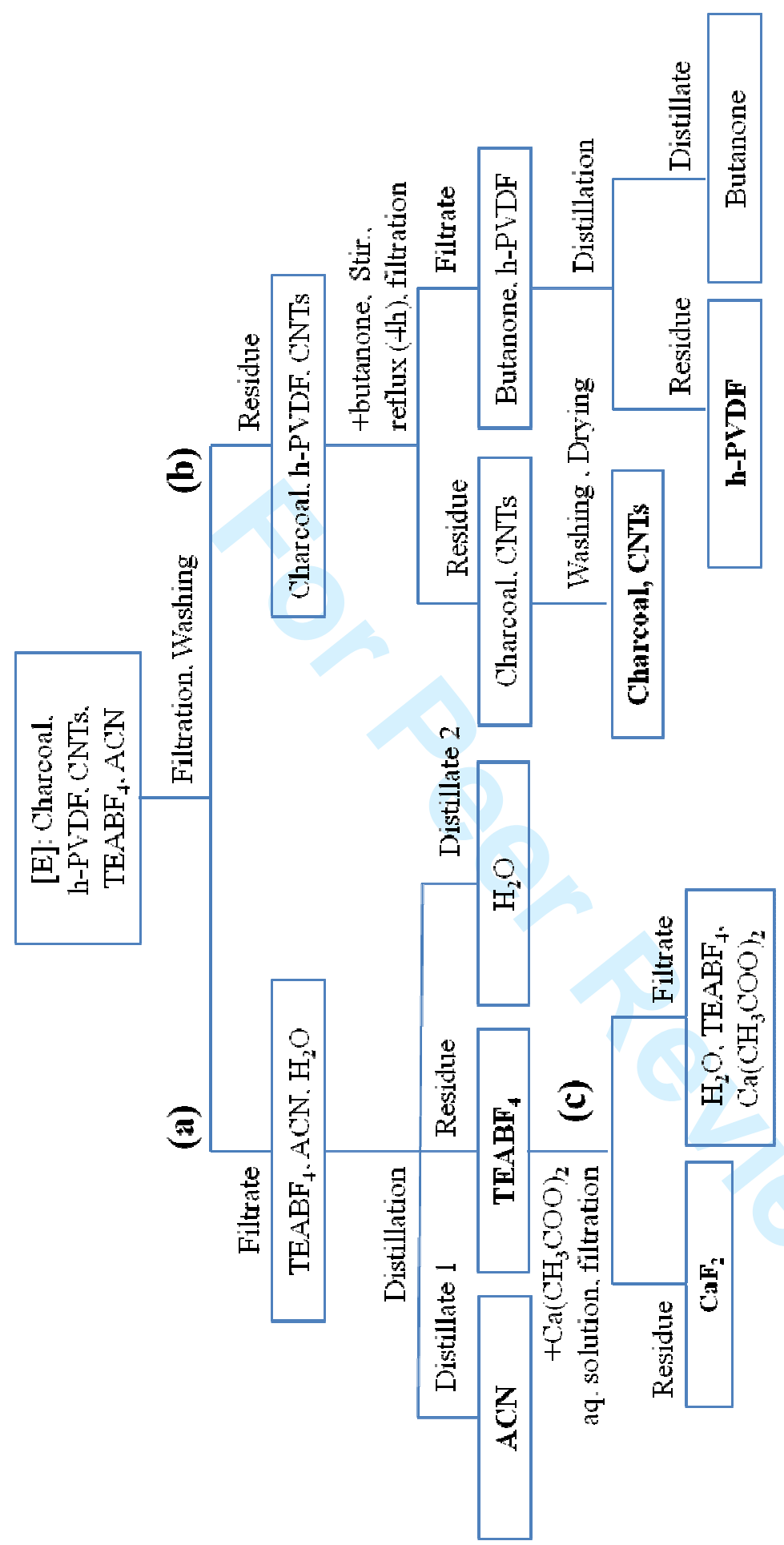

Figure 3. This diagram describes (a) the removal and isolation of $\mathrm{ACN}$ and $\mathrm{TEABF}_{4}$, (b) the purification of carbonaceous material and (c) the post treatment of $\mathrm{TEABF}_{4}$ in aqueous environment. 
REMOVAL AND ISOLATION OF ACN AND TEABF 4 : The slurry [E] (section 2.2) was filtrated using common filtration paper and washed with $450 \mathrm{ml}$ distilled water at RT. The black residue was labeled SP2 dried in an oven overnight at $70{ }^{\circ} \mathrm{C}$ and an amount of $4.3 \mathrm{~g}$ was collected. The filtrate containing $\mathrm{ACN}$, water and $\mathrm{TEABF}_{4}$ was distilled in rotary evaporator (ACN: $37{ }^{\circ} \mathrm{C}, 81$ mbar, Water: $57{ }^{\circ} \mathrm{C}, 62 \mathrm{mbar}$ ). $8.9 \mathrm{~g}$ ACN were obtained for $\sim 50$ min which correspond to recovery of ACN $59.3 \%$. Then water was partially removed and the residue was spread in a piece of glass to dry in air. The dried material weighed $1.6 \mathrm{~g}$. Since it contained some carbon traces it was dissolved again in $80 \mathrm{ml}$ distilled water and centrifuged to remove the precipitated carbon. The clean supernatant was left to dry in air. The dry compound which weighed $1.4 \mathrm{~g}$ was assigned to $\mathrm{TEABF}_{4}$ crystallized differently from the initially used $\mathrm{TEABF}_{4}$, conclusion derived by XRD (Figure 5) since the intensity ratio of the peaks has changed and FTIR spectrum (Figure 6). The calculated recovery of $\mathrm{TEABF}_{4}$ was $70 \%$. In the FTIR spectrum of the initially used $\mathrm{TEABF}_{4}\left(\mathrm{C}_{8} \mathrm{H}_{20} \mathrm{NBF}_{4}\right)$ the frequencies around $2994 \mathrm{~cm}^{-1}$ are attributed to $\mathrm{CH}_{3} \mathrm{CH}_{2}$ groups with the $\delta$ asymmetric and symmetric $\mathrm{CH}_{2}$ frequencies found at $1492 \mathrm{~cm}^{-1}$ and $1397 \mathrm{~cm}^{-1}$ correspondingly. The $\mathrm{CH}_{2}$ twist mode is seen at $1307 \mathrm{~cm}^{-1}$. The peak at $1172 \mathrm{~cm}^{-1}$ represents the $\mathrm{CH}_{3}$ rocking mode of $\mathrm{C}_{2} \mathrm{H}_{5}$ group. The $\mathrm{C}-\mathrm{C}$ asymmetric and $\mathrm{C}-\mathrm{N}$ asymmetric frequencies are represented by the peaks at $1087 \mathrm{~cm}^{-1}$ and $1026 \mathrm{~cm}^{-1}$, respectively. The $\mathrm{CH}_{2}$ rocking mode is represented by the band located at $791 \mathrm{~cm}^{-1}$ (Kandhaswamy et al, 2002). The peak at $527 \mathrm{~cm}^{-1}$ is attributed to $\mathrm{B}-\mathrm{F}$ bending of $\mathrm{BF}_{4}^{-}$. We can observe the significant similarity in FTIR spectra of $\mathrm{TEABF}_{4}$ before and after recycling and purification. 


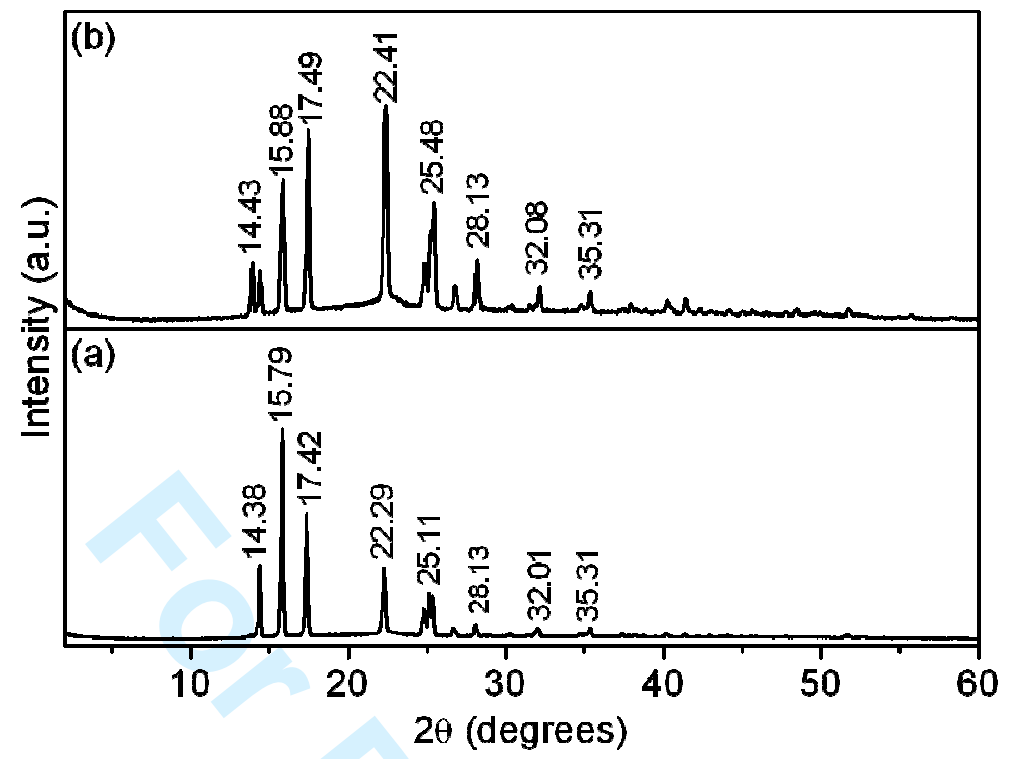

Figure 4. XRD patterns of $\mathrm{TEABF}_{4}$ (a) before recycling, (b) after recycling and purification.

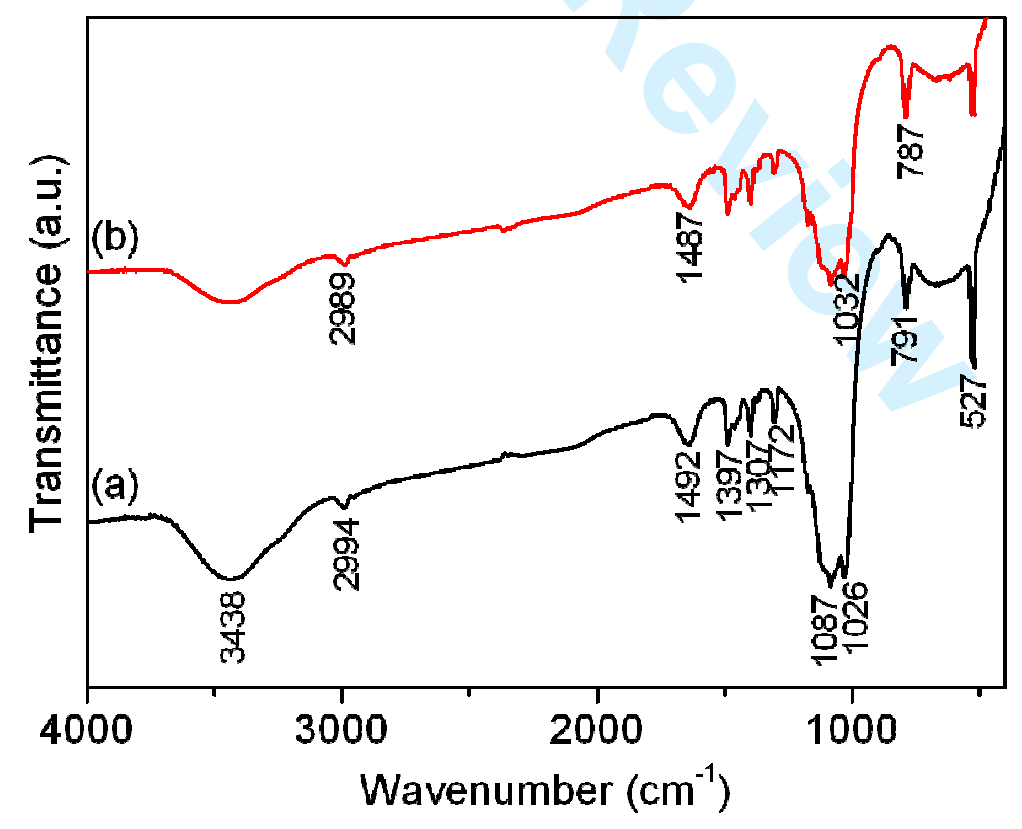

Figure 5. FTIR spectra of $\mathrm{TEABF}_{4}$ (a) before recycling and (b) after recycling and purification. 
PURIFICATION OF CARBONACEOUS MATERIAL: $4.2 \mathrm{~g}$ of SP2 were dispersed in $100 \mathrm{ml}$ butanone and the whole was stirred under reflux for $1 \mathrm{~h}$. Then filtration took place while butanone was still warm. The black carbon material was kept on the filter and the filtrate was distilled in rotary evaporator (Butanone: $37^{\circ} \mathrm{C}, 89 \mathrm{mbar}$ ). The dry residue with weight $0.122 \mathrm{~g}$ could be assigned to remaining $\mathrm{TEABF}_{4}$ or to PVDF that has suffered changes. Since it contained carbon traces, the material was redissolved in butanone under reflux and filtrated using filtrate paper: Schleicher \& Schüll, Ref No 300110. The clean filtrate was left to dry in air and the obtained white powder weighed $0.090 \mathrm{~g}$. From FTIR (Figure 7) and XRD (Figure 8) characterization it is evident that the spectrum contains bands that could be attributed to both PVDF and $\mathrm{TEABF}_{4}$ traces. In Figure $7 \mathrm{a}$, the infrared bands at $\sim 3023 \mathrm{~cm}^{-1}$ and $2983 \mathrm{~cm}^{-1}$ are assigned to asymmetric and symmetric modes of $\mathrm{CH}_{2}$ group. The very strong band at $1407 \mathrm{~cm}^{-1}$ is assigned to $\mathrm{CH}_{2}$ wagging mode. The strong band at $1077 \mathrm{~cm}^{-1}$ is assigned to $\mathrm{CC}$ asymmetric mode. The distinct band at $882 \mathrm{~cm}^{-1}$ is determined by the $\mathrm{CC}$ asymmetric stretching vibration. The very strong band appearing at $1187 \mathrm{~cm}^{-1}$ represents coupling of the $\mathrm{CF}_{2}$ asymmetric stretching mode and $\mathrm{CC}$ symmetric mode. The band at $1282 \mathrm{~cm}^{-1}$ is connected with $\mathrm{CF}_{2}$ asymmetric stretching. The band at 842 $\mathrm{cm}^{-1}$ is assigned to the symmetric stretching vibration of the $\mathrm{CC}$ bond. The $\mathrm{CF}_{2}$ bending vibration is assigned to the strong band at $767 \mathrm{~cm}^{-1}$. The $\mathrm{CF}_{2}$ wagging mode is associated with strong band at $617 \mathrm{~cm}^{-1}$ and the band at $491 \mathrm{~cm}^{-1}$ corresponds to the $\mathrm{CF}_{2}$ rocking vibration (Nallasamy et al, 2005). The white powder that is obtained after this purification process has characteristic bands in FTIR spectrum that could be assigned both to h-PVDF or $\mathrm{TEABF}_{4}$. The same conclusion is derived by XRD pattern of this material when it is compared with the XRD patterns of h-PVDF and $\mathrm{TEABF}_{4}$ 


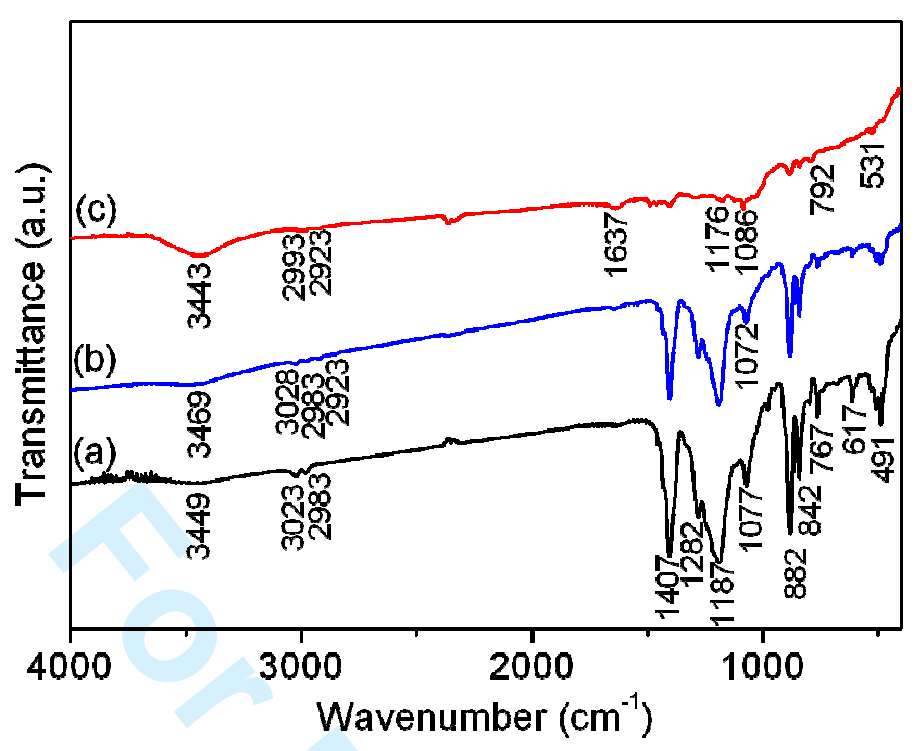

Figure 6. FTIR spectra of PVDF (a) before recycling, (b) thermally treated at $120{ }^{\circ} \mathrm{C}$ for $2 \mathrm{~h}$ in air (h-PVDF) and (c) white powder after purification with butanone.

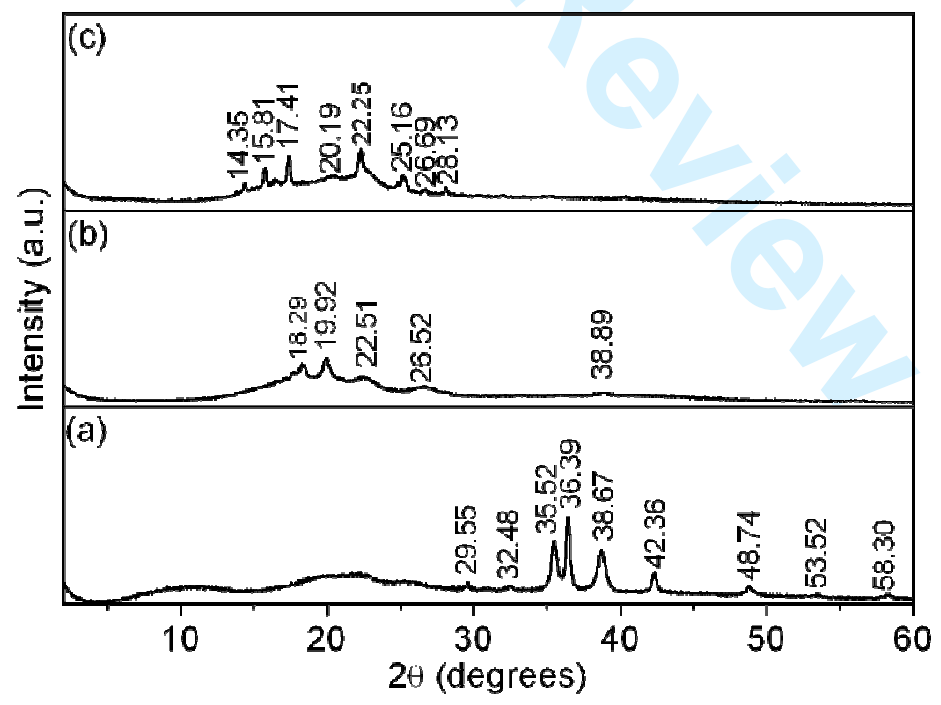

Figure 7. XRD patterns of PVDF (a) initially used in the slurry of the simulated supercapacitor, (b) thermally treated at $120{ }^{\circ} \mathrm{C}$ for $2 \mathrm{~h}$ in air (h-PVDF), and (c) the white powder obtained after the purification process with butanone. 
As we can observe from the XRD patterns when PVDF is heated at $120{ }^{\circ} \mathrm{C}$ as in the case of the simulated supercapacitor slurry, it suffers structural changes and the XRD pattern before the treatment (Figure 8a) is different than that after the treatment (Figure $8 \mathrm{~b}$ ). On the other hand if we compare the XRD pattern of the PVDF with the recycled $\mathrm{TEABF}_{4}$ we can see that the white powder obtained after purification with butanone has an XRD pattern (Fig. 8c) with characteristic peaks both of $\mathrm{TEABF}_{4}$ (Figure 5b) and h-PVDF. Probably this powder contains traces from $\mathrm{TEABF}_{4}$ that was not removed with dissolution in water and traces from PVDF that has suffered structural alterations due to heating at $120{ }^{\circ} \mathrm{C}$ for $2 \mathrm{~h}$, which is a necessary step towards preparation of the simulated supercapacitor.

CARBON MATERIAL: The carbon material of the above process was washed successively with water and acetone and left to dry in air. It weighed $3.9 \mathrm{~g}$ and was labeled SP3. In Figure 9, the FTIR spectra of the main carbon ingredients that were initially used i.e. activated charcoal and CNTs as well as the FTIR spectra of SP1 (before recycling) and SP3 (final carbonaceous material after recycling) are presented. As it can be observed there are not significant differences in FTIR characteristics between the initial carbonaceous material SP1 and the recycled material SP3. Both bear characteristic bands of activated charcoal and CNTs ingredients. The band in the range $3449-3465 \mathrm{~cm}^{-1}$ is due to the absorption of water molecules (Figures 9a-d), while the two bands at $2852-2932 \mathrm{~cm}^{-1}$ are attributed to $\mathrm{C}-\mathrm{H}$ interaction with the surface of the carbon. Moreover, the band in the range $1577-1664 \mathrm{~cm}^{-1}$ may be attributed to the aromatic carbon-carbon stretching vibration. However, it must be indicated that the bands in the range of $3200-3650 \mathrm{~cm}^{-1}$ can be also attributed to the hydrogen bonded $\mathrm{OH}$ group of alcohols and phenols (Yang et al, 2003) that can give 
rise to peak centered at 1387 or $1384 \mathrm{~cm}^{-1}$ assigned to $\mathrm{C}-\mathrm{OH}$. The morphological characteristics of SP3 are presented in Figure 10.

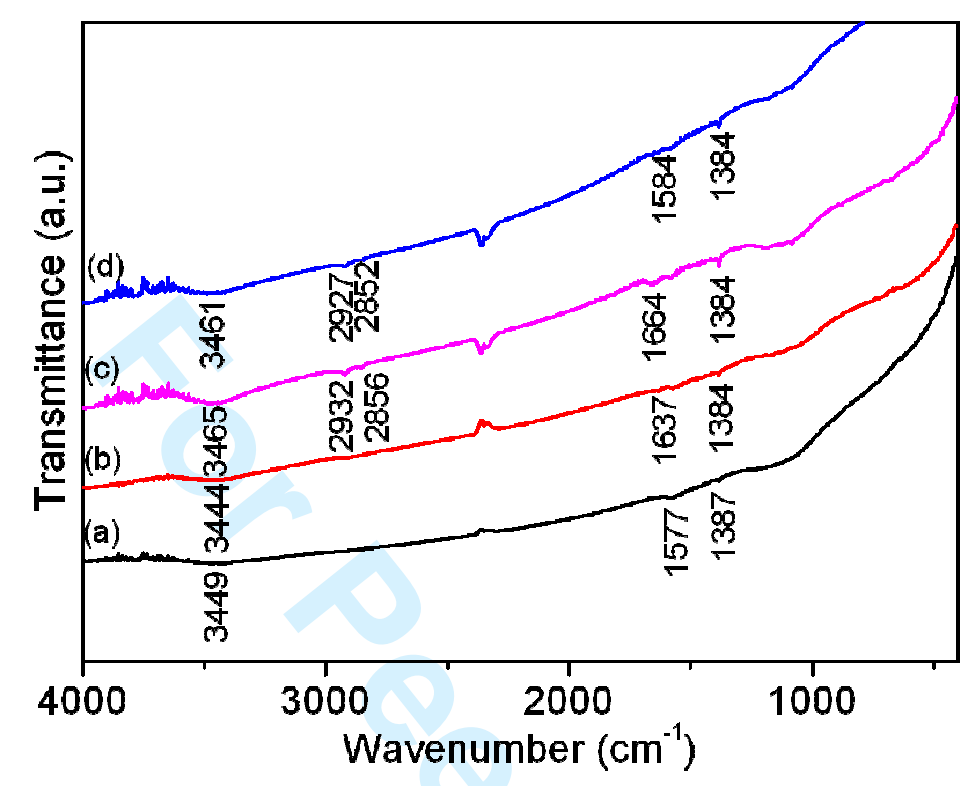

Figure 8. FTIR spectra of (a) initial activated charcoal, (b) initial CNTs, (c) SP1 containing activated charcoal, CNTs and h-PVDF and (d) carbonaceous material after recycling SP3.
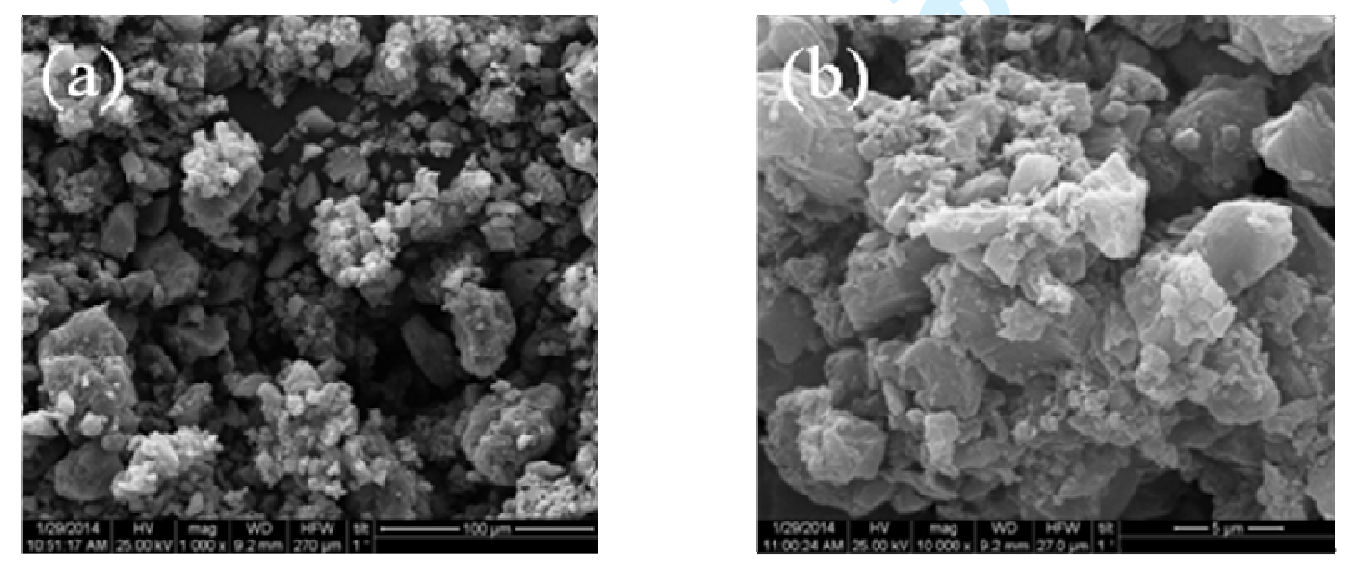

Figure 19. SEM images of the recycled carbonaceous material SP3 in two different magnifications (a) x1000 and (b) x10000. 


\section{CYCLIC VOLTAMMETRY MEASUREMENTS OF THE RECYCLED CARBON}

\section{MATERIAL}

The electrode active material was prepared from the recycled (SP3) material in order to assess the possibility of its reutilization. The slurry for the electrode material contained $95 \%$ SP3 and $5 \%$ PVDF binder. Thus, $1 \mathrm{~g}$ SP3 was dispersed in $3.0 \mathrm{~g}$ NMP followed by addition of $0.053 \mathrm{~g}$ PVDF under stirring. This slurry was spread on aluminum foil with the help of a film applicator Elcometer 3620 (Elcometer SA, Belgium) using $90 \mu \mathrm{m}$ film gap. After drying in furnace at $120^{\circ} \mathrm{C}$ for $2 \mathrm{~h}$, two circular electrodes of the material with apparent area of $1.33 \mathrm{~cm}^{2}$ were cut. The electrode material loading was $2.4 \mathrm{mg} / \mathrm{cm}^{2}$. The electrodes were positioned in the test cell with Macherey Nagel MN13 filter paper in between for mechanical separation of the electrodes. The $\mathrm{TEABF}_{4}$ solution in $\mathrm{ACN}$ mentioned in Section 2.2 was used as an electrolyte. All the cyclic voltammetry experiments were carried out at room temperature $\mathrm{T} \sim 25^{\circ} \mathrm{C}$.

The $\mathrm{CV}$ measurements were done in a potential window from $-2 \mathrm{~V}$ to $+2 \mathrm{~V}$ at a potential scan rate of $0.1 \mathrm{~V} / \mathrm{s}$ (Figure 11 ). The specific capacitance $\widetilde{C}_{C V}$ of the electrode material was calculated taking into account its relationship with the measured capacitance of two-electrode cell $C_{C V}$ and applying integration over the area enclosed within the CV loop as follows:

$$
\widetilde{C}_{C V}=\frac{2 C_{C V}}{m} ; C_{C V}=\frac{1}{2 \Delta V S} \int i d V
$$

where $\mathrm{m}$ is the mass of single electrode material, $\Delta \mathrm{V}$ is the potential window $(\Delta \mathrm{V}=4)$, $\mathrm{s}$ is the scan rate and $\mathrm{i}$ is a current response at a given potential $\mathrm{V}$. 


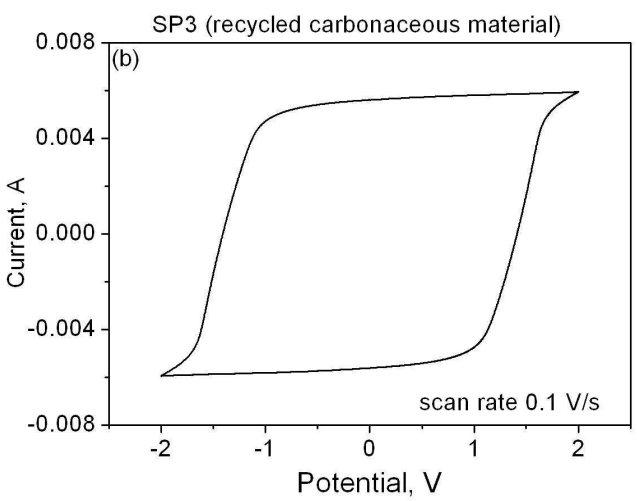

Figure 10. CV loop for the recycled material at potential scan rate $0.1 \mathrm{~V} / \mathrm{s}$.

The recycled material electrode shows rectangular shape of the CV loop that is indicative of the material capacitive behavior. The calculated specific capacitance was $25 \mathrm{~F} / \mathrm{g}$. This result confirms our expectations that the recycling procedure allows further reutilization of the carbonaceous materials.

\section{POST-TREATMENT OF RECYCLED TEABF 4 :}

Trapping of $\mathrm{F}^{-}$resulting from hydrolysis of $\mathrm{BF}_{4}^{-}$with $\mathrm{Ca}^{2+}$.

It has been established (Yoshioka et al, 2007) that $\mathrm{BF}_{4}^{-}$in an aqueous solution hydrolyzes according to the following equation:

$\mathrm{BF}_{4}^{-}+3 \mathrm{H}_{2} \mathrm{O} \leftrightarrow \mathrm{H}_{3} \mathrm{BO}_{3}+4 \mathrm{~F}^{-}+3 \mathrm{H}^{+}$

A very slow decomposition of $\mathrm{BF}_{4}^{-}$in aqueous solution has been noticed (Katagiri et al, 2006). Based on the aforementioned findings we went on capturing $\mathrm{F}^{-}$anions by $\mathrm{Ca}^{2+}$ cations stemming from dissolved in water $\mathrm{Ca}\left(\mathrm{CH}_{3} \mathrm{COO}\right)_{2} \cdot \mathrm{H}_{2} \mathrm{O}$. The following reaction that converts $\mathrm{F}^{-}$to a non toxic compound insoluble $\mathrm{CaF}_{2}$ was utilized:

$\mathrm{Ca}^{2+}+\mathrm{F}^{-} \leftrightarrow \mathrm{CaF}_{2}$

Specifically: $0.5 \mathrm{~g} \mathrm{TEABF}_{4}$ was dissolved in $20 \mathrm{ml}$ distilled water [F]. $0.7 \mathrm{~g} \mathrm{Ca}$ $\left(\mathrm{CH}_{3} \mathrm{COO}\right)_{2} \cdot \mathrm{H}_{2} \mathrm{O}$ were dissolved in $100 \mathrm{ml}$ distilled water [G]. [F] was added to [G] 
and stirring was kept for $5 \mathrm{~h}$ and left without stirring for 1.5 months. The whole was centrifuged, washed with water and ethanol and the residue which weighed $0.057 \mathrm{~g}$ was labeled [H]. It was assigned to $\mathrm{CaF}_{2}$ conclusion derived from XRD (Figure 12a) and FTIR results (Figure 12b) in accordance with literature (Tahvildaril et al, 2012). The very small amount of $\mathrm{CaF}_{2}$ obtained indicated a very slow hydrolysis of $\mathrm{BF}_{4}^{-}$
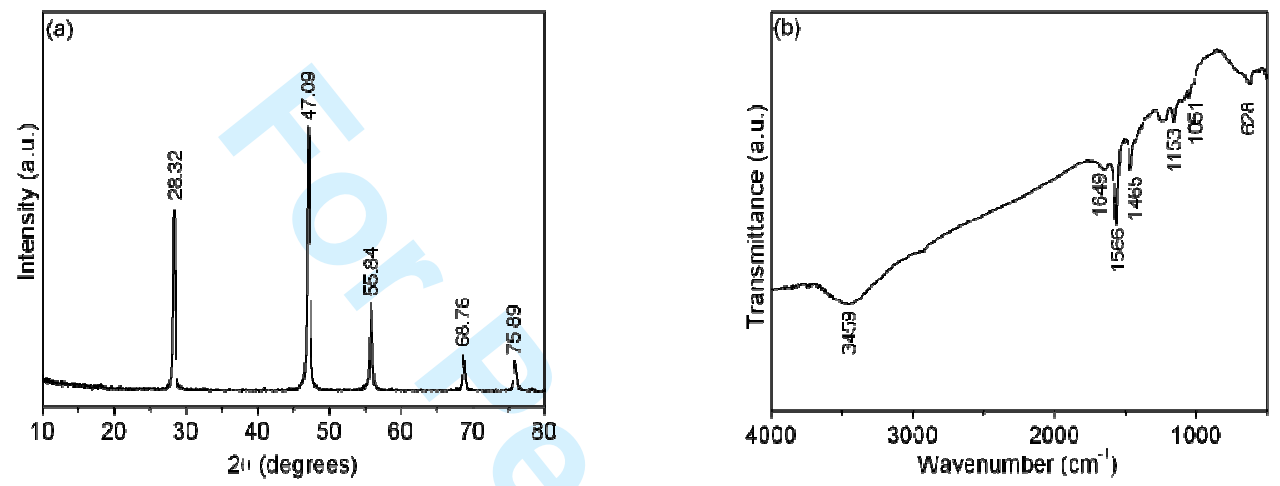

Figure 11. (a) XRD pattern and (b) FTIR spectrum of $\mathrm{CaF}_{2}$ that was formed by the reaction of $\mathrm{F}^{-}$ions (stemming from hydrolysis of $\mathrm{BF}_{4}^{-}$) and $\mathrm{Ca}^{2+}$.

\section{Conclusions}

A simple, facile and low cost method for recycling of supercapacitor materials was proposed. Recovering of some major components of a used supercapacitor was described. Extraction of the electrolyte $\mathrm{TEABF}_{4}$ from the carbonaceous material led to a recovery up to $\sim 70 \%$. The recovered $\mathrm{TEABF}_{4}$ crystallized differently from the initially used $\mathrm{TEABF}_{4}$. A handling procedure of this toxic material in wastewater was proposed. The recovery of $\mathrm{ACN}$ was up to $59.3 \%$. Its purification from $\mathrm{TEABF}_{4}$ and PVDF traces was performed via treatment with volatile, non-toxic solvent butanone. The recycled carbonaceous material had not suffered significant changes during these treatments and bore characteristics of the two carbon ingredients, activated charcoal 
and CNTs. Additionally the recycled carbonaceous material still exhibits supercapacitor behavior, so that it can be reused. The equipment had low cost and environmentally friendly reagents were employed for the recycling procedures.

\section{Acknowledgement}

The financial support from the FP7 project AUTOSUPERCAP is highly appreciated.

\section{References}

Asokan P, Saxena M, Asolekar SR (2005) Coal combustion residues- environmental implications and recycling potentials. Resources, Conservation and Recycling 43: 239-262.

Bo Z, Wei-min C, Pin-jing HE (2007) Influence of lactic acid on the two-phase anaerobic digestion of kitchen wastes. Journal of Environmental Science 19: 244-249.

Chen WC, Hu CC, Wang CC, Min CK (2004) Electrochemical characterization of activated carbon-ruthenium oxide nanoparticles composites for supercapacitors. Journal of Power Sources 125: 292-298.

de Marco I, Caballero BM, Cabrero MA, Laresgoiti MF, Torres A, Chomón MJ (2007) Recycling of automobile shredder residues by means of pyrolysis. Journal of Analytical and Applied Pyrolysis 79: 403-408.

Fedorovskaya EO, Bulusheva LG, Kurenya AG, Asanov IP, Rudinac NA, Funtov KO, Lyubutin IS, Okotrub AV (2014) Supercapacitor performance of vertically aligned multiwall carbon nanotubes produced by aerosol-assisted CCVD method. Electrochimica Acta 139: 165-172. 
Howarth J, Mareddy SSR, Mativenga PT (2014) Energy intensity and environmental analysis of mechanical recycling of carbon fibre composite. Journal of Cleaner Production 81: 46-50.

Jain A, Tripathi SK (2014) Fabrication and characterization of energy storing supercapacitor devices using coconut shell based activated charcoal electrode. Materials Science and Engineering B 183: 54-60.

Jiang G, Pickering SJ, Walker GS, Wong KH, Rudd CD (2008) Surface characterization of carbon fibre recycled using fluidized bed. Applied Surface Science 254: 2588-2593.

Jiang G, Pickering SJ, Lester EH, Turner TA, Wong KH, Warrior NA (2009) Characterisation of carbon fibres recycled from carbon fibre/epoxy resin composites using supercritical n-propanol. Composites Science and Technology 69: 192-198.

Kandhaswamy MA, Srinivasan V (2002) Synthesis and characterization of tetraethylammonium tetrachlorocobaltate crystals. Bulletin of Materials Science 25(1): 41-45.

Katagiri J, Yoshioka T, Mizoguchi T. (2006) Basic study on the determination of total boron by conversion to tetrafluoroborate ion $\left(\mathrm{BF}_{4}{ }^{7}\right)$ followed by ion chromatography. Analytical Chimica Acta 570: 65-72.

Kennerley JR, Kelly RM, Fenwick NJ, Pickering SJ, Rudd CD (1998) The characterisation and reuse of glass fibres recycled from scrap composites by the action of a fluidised bed process. Composites Part A 29A: 839-845.

Kötz R, Carlen M (2000) Principles and applications of electrochemical capacitors. Electrochimica Acta 45: 2483-2498. 
Laurijssen J, Marsidi M, Westenbroek A, Worrell E, Faaij A (2010) Paper and biomass for energy? The impact of paper recycling on energy and $\mathrm{CO}_{2}$ emissions. Resources, Conservation and Recycling 54: 1208-1218.

Liu C, Zhenning Yu Z, Neff D, Zhamu A, Jang BZ (2010) Graphene-Based Supercapacitor with an Ultrahigh Energy Density. Nano Letters 10(12): 48634868 .

López-Fonseca R, Duque-Ingunza I, de Rivas B, Arnaiz S, Gutiérrez-Ortiz JI (2010) Chemical recycling of post-consumer PET wastes by glycolysis in the presence of metal salts. Polymer Degradation and Stability 95: 1022-1028.

Lotfi S, Deja J, Rem P, Mróz R, van Roekel E, van der Stelt H (2014) Mechanical recycling of EOL concrete into high-grade aggregates. Resources, Conservation and Recycling 87: 117-125.

Luo L, Yuan J, Xie P, Sun J, Guo W (2013) Hydrodynamics and mass transfer characteristics in an internal loop airlift reactor with sieve plates. Chemical Engineering Research and Design 91: 2377-2388.

Merrild H, Larsen AW, Christensen TH (2012) Assessing recycling versus incineration of key materials in municipal waste: The importance of efficient energy recovery and transport distances. Waste Management 32: 1009-1018.

Morris (1996) Recycling versus incineration: an energy conservation analysis. Journal of Hazardous Materials 47: 277-293.

Miyamoto Y (2003) Ecomaterials synthesis and recycling by nitriding combustion. Current Opinion in Solid State and Materials Science 7: 241-245.

Nallasamy P, Mohan S (2005) Vibrational spectroscopic characterization of form II poly (vinylidene fluoride). Indian journal of Pure \& Applied Physics 43: 821827. 
Nishida Y (2001) Recycling of metal matrix composites. Advanced Engineering Materials 5: 315-317.

Oliveux G, Bailleul JL, Le Gal La Salle E, Lefèvre N, Biotteau G (2013) Recycling of glass fibre reinforced composites using subcritical hydrolysis: Reaction mechanisms and kinetics, influence of the chemical structure of the resin. Polymer Degradation and Stability 98: 785-800.

Pang EJX, Chan A, Pickering SJ (2011) Thermoelectrical properties of intercalated recycled carbon fibre composite. Composites: Part A 42: 1406-1411.

Petterson J, Nilson P (1994) Recycling of SMC and BMC in standard process equipment. Journal of Thermoplastic Composite Materials 7: 56-63.

Pickering SJ (2006) Recycling technologies for thermoset composite materials-current status. Composites Part A 37: 1206-1215.

Pickering SJ, Kelly RM, Kennerley JR, Rudd CD, Fenwick NJ (2000) A fluidized-bed process for the recovery of glass fibres from scrap thermoset composites. Composites Science and Technology 60: 509-523.

Pimenta S, Pinho ST, Robinson P, Wong KH, Pickering SJ (2010) Mechanical analysis and toughening mechanisms of a multiphase recycled CFRP. Composites Science and Technology 70: 1713-1725.

Piñero-Hernanz R, Dodds C, Hyde J, García-Serna J, Poliakoff M, Lester E, Cocero MJ, Kingman S, Pickering S, Wong KH (2008) Chemical recycling of carbon fibre reinforced composites in near critical and supercritical water. Composites Part A 39: 454-461.

Plichta A, Lisowska P, Kundys A, Zychewicz A, Dębowski M, Florjańczyk Z (2014) Chemical recycling of poly(lactic acid) via controlled degradation with protic (macro) molecules. Polymer Degradation and Stability 108: 288-296. 
Richard GM, Mario M, Javier T, Susana T (2011) Optimization of the recovery of plastics for recycling by density media separation cyclones. Resources, Conservation and Recycling 55: 472-482.

Santini A, Passarini F, Vassura I, Serrano D, Dufour J, Morselli L (2012) Auto shredder residue recycling: Mechanical separation and pyrolysis. Waste Management 32: 852-858.

Song X, Wang H, Yang X, Liu F, Yu S, Liu S (2014) Hydrolysis of poly(lactic acid) into calcium lactate using ionic liquid $[\mathrm{Bmim}][\mathrm{OAc}]$ for chemical recycling. Polymer Degradation and Stability 110: 65-70.

Tahvildari K, Esmaeili pour M, Ghammamy S, Nabipour $\mathrm{H}$ (2012) $\mathrm{CaF}_{2}$ nanoparticles: Synthesis and characterization. International Journal of Nano Dimension 2(4): 269-273.

Tsintzou GP, Antonakou EV, Achilias DS (2012) Environmentally friendly chemical recycling of poly(bisphenol-A carbonate) through phase transfer-catalysed alkaline hydrolysis under microwave irradiation. Journal of Hazardous Materials 241-242: 137- 145.

Vermisoglou EC, Devlin E, Giannakopoulou T, Romanos G, Boukos N, Psycharis V, Lei C, Lekakou C, Petridis D, Trapalis C (2014) Reduced graphene oxide/iron carbide nanocomposites for magnetic and supercapacitor applications. Journal of Alloys and Compounds 590: 102-109.

Wang D, Wang X (2011) Self-Assembled Graphene/Azo Polyelectrolyte Multilayer Film and Its Application in Electrochemical Energy Storage Device. Langmuir 27(5): 2007-2013.

Wang L, Templer R, Murphy RJ (2012) A Life Cycle Assessment (LCA) comparison of three management options for waste papers: Bioethanol production, 
recycling and incineration with energy recovery. Bioresource Technology 120: 89-98.

Wang X, Yin Y, Li X, You Z (2014) Fabrication of a symmetric micro supercapacitor based on tubular ruthenium oxide on silicon 3D microstructures. Journal of Power Sources 252: 64-72.

Wong KH, Pickering SJ, Rudd CD (2010) Recycled carbon fibre reinforced polymer composite for electromagnetic interference shielding. Composites: Part A 41: $693-702$.

Yang T, Lua AC (2003) Characteristics of activated carbons prepared from pistachionut shells by physical activation. Journal of Colloid and Interface Science 267: 408-417.

Yang Y, Boom R, Irion B, van Heerden D-J., Kuiper P, de Wit H (2012) Recycling of composite materials. Chemical Engineering and Processing 51: 53-68.

Yoshioka T, Kameda T, Miyahara M, Uchida M, Mizoguchi T, Okuwaki A (2007) Removal of tetrafluoroborate ion from aqueous solution using magnesiumaluminum oxide produced by the thermal decomposition of a hydrotalcite-like compound. Chemosphere 69: 832-835. 